Edwin C. Mensah, Christopher Ziemnowicz, and John A. Parnell

\title{
CRISIS PERCEPTION, EXPERIENCE, AND PREPAREDNESS AMONG MANAGERS IN GHANA
}

\begin{abstract}
Research about organizations and possible crisis events that may affect their operations or have negative consequences is wide-ranging. Recommendations include establishing crisis management plans and developing alternatives to deal with potential disasters. Most of the crisis management literature focuses on large businesses in developed countries. This study surveys the perceptions, preparedness, and involvement concerning crisis occurrences among managers in Ghana, an emerging nation. Initial findings suggest indigenous Ghanaian managers recognize the need for crisis preparation, but at the same time, may not invest the time, energy, and resources that are needed to be prepared. This study shows that Ghanaian firms with foreign ownership or control have in place crisis management policies typically found within large international businesses. This paper outlines the crisis management background and literature, presents the situation in Ghana, and reports on the survey conducted in Ghana. Our suggestions should assist managers of indigenous firms in Ghana

Keywords: Ghana, Crisis management, Disasters, Indigenous firms, International business, Preparedness
\end{abstract}

Edwin C. Mensah

Thomas School of Business, University of North Carolina at Pembroke

Christopher Ziemnowicz

Thomas School of Business, University of North Carolina at Pembroke

John A. Parnell

College of Business and Technology, University of North Alabama

Correspondence: Edwin C. Mensah

University of North Carolina at Pembroke, Thomas School of Business

One University Drive, Pembroke, North Carolina 28372-1510

E-mail: edwin.mensah@uncp.edu

Journal of International Business and Economy

Spring 2021 


\section{INTRODUCTION}

Crisis management has received research interest in developed nations and large organizations (Crandall, Parnell, and Spillan, 2014; Lalonde and Roux-Dufort, 2013). There has been less analysis of crisis management awareness among organizations in developing nations (Arpan and Sun, 2006; Dadzie, Winston, and Dadzie, 2012; Herbane, 2013; Sawalha, Jraisat, and Quauh, 2013) such as Ghana (Agyapong and Boamah, 2013; Agyapoing and Muntaka, 2012; Mahmoud, 2011). However, developing countries continue to experience many natural and man-made catastrophes causing human suffering as well as being detrimental to their economies. This paper investigates crisis readiness in Ghana, a growing emerging nation in West Africa. We selected Ghana for the study because of its cultural and economic differences compared to developed nations. Our work replicates the investigation conducted by Parnell, Koseoglu, and Spillan (2010) that surveyed the crisis perceptions and readiness of managers in Turkey and the United States.

A crisis can be a turning point where events or activities risk escalating in intensity, interfere with the normal operations of the business, jeopardize an organization's image, or damage its financial condition in any way (Fink, 1986). This characterization is associated with a broad category of events and incidents that can affect an organization. Examples include unexpected events such as natural disasters, product failures, scandals, etc. Numerous crisis events over the years have highlighted the importance of being ready. Preparation typically lessens some of the distress and costs of a disaster event. Given the increasing rates and diversity of misfortunes, along with examples of ineffective management decisions, has given crisis management increased attention across the globe (Lalonde and Roux-Dufort, 2013; Parnell, 2021).

Crisis management is a method for planning and dealing with unexpected events that affect an organization. Also known as business continuity management, disaster planning, or contingency planning, the field of crisis management has been recognition as organizations in dynamic environments confront new and more sophisticated threats that can affect their functioning and even survival. This management approach involves a variety of components, starting with an appraisal of vulnerabilities and organizational priorities. Most large organizations have developed crisis management plans and organized teams in case a crisis strikes. However, enterprises often appear unprepared. The most serious management error is to assume that a crisis will never occur. Denial is a ruinous response to a crisis when one occurs. In short, effective crisis planning and execution of a 
plan have shown to provide a degree of control over the crisis, and perhaps turn the problem into an advantage for the enterprise (Wilderoter, 1987).

Managers of many small businesses tend to avoid preparing for a crisis (McCartney, Crandall and Ziemnowicz, 1999). Nevertheless, small firms may face a large variety of misfortunes, and their managers' abilities to successfully deal with a sudden emergency can spell the difference between survival and ruin. Unfortunately, managers often perceive that "crises don't happen in our industry/field" or "we have a well-managed business and could manage our way through a crisis without a plan" (Caponigro, 2000). A study of Guatemalan small business managers found that they are not that concerned about crisis issues because they experience fewer crisis events relative to larger organizations and thus, their perceived need to plan for a crisis is not as strong as large business managers (Spillan and Ziemnowicz, 2007). Simbo (1993) noted that businesses lack effective crisis management plans because they have not even acknowledged any major crisis events that could impact them. Their managers do not have the tools needed for a crisis event. There are four typical assumptions within some of the smaller organizations:

- Crisis events only happen to other organizations or are somehow protected from crisis (Mitroff, Pauchant, Finney, and Pearson, 1989).

- Insurance policies cover losses or interruptions that a crisis may cause (Mahul, 2001).

- Managers do not have the resources or the time to establish plans or readiness requirements (Barton, 1993).

- Potential crises can be varied and challenging, making it difficult for organizations to plan for tomorrow's uncertainties (Caponigro, 2000).

In business practice, strategic and crisis management processes are often contextspecific (Balamir, 2002; London and Hart, 2004; Ouedraogo, 2007; Ralston, Holt, Terpstra, and Kai-Cheung, 2008; Reid, 2000; Zhang, Zhang, and Liu, 2007; Zhou, Tse, and Li, 2006). Beyond related organizational crises, there are also broader events that affect smaller enterprises in developing nations. How managers in emerging countries view crisis management and why their perceptions may differ from those in developed economies is significant. Evidence suggest that perceptions about and previous experience with organizational crises are vital determinants in the steps which managers take to prepare for them (Herbane, 2013). Studies conducted in Africa are often focused and overwhelmed with the continent's numerous major problems, to the point of describing 
the nations as being in constant crises (Hope, 2002). These studies also focus on crisis management approaches related to the development and the public health, security, food, or military sectors. Continuing violence, political uncertainties, economic shocks, social tensions, environmental problems, and demographic shifts are potential broad-based crisis occurrences in Africa (Lewis and Harbeson, 2016; Olsen, 2011). However, African nations also have diverse attributes and capabilities to cope with or mitigate these dire circumstances. Their needs for capacity building for crisis management have been acknowledged (Garuba, 1998). However, research and preparedness efforts have been focused primarily on regional organizations and national governments to develop mechanisms and adapt their structures to respond to crises (Faria, 2004). Less documentation is available for indigenous organizations and their managers.

The influence of culture in management effectiveness is well documented, especially in leadership, strategic management, motivation, organization structure, organizational learning, and conflict management (Bass, 1990, 1996; James, Wooten, and Dushek, 2011; House, Wright, and Aditya, 1997; Parnell, Crandall, Xihui, and Long, 2007; Wasti, Tan, Brower, and Önder et al., 2007; Wright and Aditya, 1997). Moreover, culture at the organizational level is a key influencer of an organization's response to a crisis (Mitroff, 1988; Parnell et al., 2007). Marked cultural distinctions in Ghana are clear, most notably in two of Hofstede's (1991) cultural dimensions. Ghana scores very high on Power Distance Index (PDI) with a score of 80, but very low on Individuality (IDV) with a score of 15 (Hofstede, 1980, 1991). Power distance has been linked to crisis response effectiveness in cross-cultural studies (Koc, 2013).

Investigating businesses in different nations also provides valuable insights into some of the worst-case scenarios that are part of the crisis management process. This study provides insights on crisis management from a developing country perspective. Importantly, this paper contributes to the literature by emphasizing that multinational company (MNC) involvement in developing nations also enhances the skill set of indigenous managers to deal with crises. Three questions can be evaluated:

- Has the crisis event occurred in the recent past?

- What is the current level of concern for that particular crisis?

- Are there any unique characteristics of the country that would increase the likelihood of a particular type of crisis?

A crisis that has occurred in the recent past can become a candidate for future worst-case scenario planning. Characteristics specific to a region may dictate what types of 
crises should be included in worst-case scenario planning. Such considerations range from natural events such as storms and earthquakes to human-induced crisis events such as raids on businesses by US Immigration and Customs Enforcement (Shapiro, Contreas, and Blanchard, 2019; Leyro and Stageman, 2018). Therefore, crisis research in other nations can broaden perspectives concerning how different types of events can provide for better preparation and resiliency for decision-makers facing arduous conditions. This includes examining systemic barriers to deal with crisis events within developing counties that may include the status quo of depending on the central government for taking actions or using "paramilitary" methods in disaster management (Al-Nammari and Alzaghal, 2015).

Managers in developing nations such as Ghana need to deal with numerous problems and challenges within their organizations (Acquaah, 2011). The objective of this study is to evaluate crisis perception and management approaches. The first section of this paper summarizes the crisis management literature and the Ghanaian management context. Next, we present details of a survey of Ghanaian managers, followed by findings and conclusions.

\section{OVERVIEW OF GHANA}

Formerly called Gold Coast, Ghana is a politically stable West African nation bordering the Gulf of Guinea, a few degrees north of the Equator, with Togo on the east, Cote d'Ivoire on the west, and Burkina Faso on the north. Ghana's location provides access to large seaports, creating routes for imports and exports markets. Ghana is endowed with natural resources with a per-capita GDP of about twice that of its neighbors.

The Ghanaian economy includes a growing formal economy and a traditional, informal economy of street sellers. The most prevalent trading center is the Accra-Tema metropolitan area, which is also Ghana's most populous area, with about 3.5 million people. Capital is becoming more widely available but remains elusive to many small- and medium-sized businesses. Most retail outlets are individual proprietorships, although franchising has experienced a widespread increase in recent years. The development of a stable, multiparty democratic system along with a commitment to market reforms is attracting investors and promoting private sector growth (US Department of State, 2019). Ghana's government is committed to implementing policies to encourage investor 
confidence. This program includes $100 \%$ foreign ownership, privatization in critical economic sectors, and infrastructure development. Although Ghana's industrial sector is still emerging, it is more developed than its sub-region counterparts. Adopting quality management programs has promoted increased technical proficiency and productivity in Ghana (Fening, Pesakovic, and Amaria, 2008). The financial sector is also developing quickly.

Mining, manufacturing, construction, and electricity account for about one-third of Ghana's GDP. Ghana's primary minerals and other national resources include gold, diamond, manganese ore, bauxite with gold, and timber. Cocoa provides about a third of the nation's export revenues. Other prominent exports include palm oil, shea butter, coconuts, and coffee. Ghana enjoys quota-free access to the United States and European Union markets. Support from foreign governments and non-governmental organizations (NGOs) has promoted export growth in producing other agricultural products such as pineapples, pepper, and cashews. Petroleum exploration and related industries have received considerable attention since a significant discovery of oil off the Ghanaian coast (BBC News, 2007). As a result, Ghana is becoming one of the oil producers in the region, which contributed to an increase in the industrial sector.

\section{CRISIS AND CRISIS MANAGEMENT IN GHANA}

A diverse body of scholarly work has been published on crisis management due to the interdisciplinary nature of this area of research (Piotrowski, Watt, and Armstrong, 2010). Our definition, however, follows Coombs (2007). Thus, a crisis is an unpredictable event perceived to negatively impact an organization's performance and its stakeholders. Notwithstanding the low probability of occurrence, crisis events tend to be unexpected (Barton, 1993; Pearson and Mitroff, 1993; Sellnow and Seeger, 2001), very damaging (Irvine and Millar, 1997), and costly (Newkirk, 2001). The incidence of a crisis, therefore, requires a quick and decisive action (Crandall and Menefee, 1996; Greening and Johnson, 1996; Marra, 1998; Seeger, Sellnow, Ulmer, 1998)—since a firm's actions during a crisis could affect its reputation, financial performance, and survival (Coombs and Holladay, 2006).

Effective crisis management requires sufficient planning to address a few critical issues: (1) the knowledge of the essential crisis concerns of the entity and (2) whether the 
business has experienced a crisis. Addressing these issues enhances managerial preparedness and facilitates the development of feasible plans to forestall the incidence of a crisis (Parnell et al., 2010). Identifying potential risks could make managers more proactive in developing steps to reduce their likelihood and, if encountered, also facilitating its mitigation (Somers, 2009) and severity. A manager without sufficient information about a crisis cannot develop a plan to address it suitably (Wester, 2009).

Crisis management and readiness, however, differ between developed and emerging nations. For instance, in the developed world, open communication with journalists is the norm and highly desirable (Evans and Elphick, 2005; Gupta, 2011; Mullins, 2005), while the press and social media outlets are often restricted to information when crises occur in emerging nations. As a result, different cultures will require different responses in the incidence of a crisis (Parnell et al, 2007).

Strategic and crisis management processes are therefore context specific. Investigating other nations, such as Ghana, provides new perspectives where managers may be wise to plan contingencies for particular events. Infrastructure deficiencies and limited resources typical in developing countries such as Ghana mean that there is a higher risk and potentially more damage during natural disasters or crisis situations. An example of these problems includes the collapse of the less than one-year-old multi-story Melcom shopping center in Accra's Achimota area. Inferior design and construction contributed to this crisis, while a lack of necessary permits and safety inspections added to the loss of lives (BBC News, 2012).

An example of gaps in crisis preparation was a questionnaire of crisis management preparedness conducted by Ahorlu (2014) within a Ghanaian research institute. Many respondents were not aware of any crisis management team or plan in the organization, yet many could identify a potential crisis in the organization (Ahorlu, 2014). Research by Conill (2013) examined the information flows and communication channels in Ghana concerning disaster management environments and the low level of trust that the public places in Ghana's crisis management authorities such as the National Disaster Management Organization (NADMO). The objectives of NADMO include enhancing the capacity of society to prevent and manage disasters (NADMO, 2020).

The International Monetary Fund (IMF) noted a particular concern at the national level in 2013. The IMF reported that the Ghanaian government lacks a comprehensive crisis management plan, and the national authorities do not have full bank resolution powers to deal with a macro-economic financial exigency (Bax and Dontoh, 2014). In 
2005, the nation's debt was cleared as part of a global relief agreement for developing nations (Bax and Dontoh, 2014). The Ghanaian economy performed relatively well following the global financial crisis that began in 2008 (Ghana Business Forecast Report, 2010). However, by 2014, West Africa's second-largest economy encountered problems. Ghana's currency fell over one-third against the US dollar because of a looming currentaccount deficit (estimated to be $10 \%$ of the GDP) and the government's inability to cut spending, forcing the nation to seek assistance from the IMF (Bax and Dontoh, 2014; Parnell, 2018).

According to Conill (2013), Ghana faces recurring natural disasters that most often include flooding and some instances of epidemics. Flooding is common due to the heavy seasonal rainfall along with associated run-off compounded by drought and problems with the dams in both Ghana and in Burkina Faso to the north and tidal waves along Ghana's Atlantic coastline. Lake Volta, the largest artificial lake by surface area in the world, changed climate patterns in Ghana (Andah, van de Giesen and Biney, 2003). The deforestation, water surface area, and dams that dried up rivers affected agriculture and caused a migration to Accra with an associated increase in poor-quality unplanned settlements in the path of potential flash floods. Moreover, the demand for water by industries (hydropower generation, agriculture, mining, and domestic and industrial consumption) is increasing along with environmental pollution problems (Almoradie, de Brito, Evers, Bossa, Lumor, Norman, Yacouba, and Hounkpe, 2020).

Water supplies are severely stretched along with increasing pollution and environmental degradation. The situation worsens with population and urbanization growth, along with increases in the standard of living. Moreover, mining operations are expanding using more water while rainfall amounts have decreased over the years due to longer dry seasons, drying some of the tributaries and the main rivers. The impacts of climate change on its water resources and food security will require Ghana and its farmers to develop strategies to adapt and reduce adverse effects on people and the environment.

Compounding these problems is the low level of public trust in disaster management authorities. Oteng-Ababio (2013) found that Ghana's crisis management authority, NADMO, has a top-down approach with low cooperation, collaboration, and coordination with stakeholders, leading to devastation and destruction occur before actions are taken. The view should be that practitioners wean themselves from managing disasters and take to managing risk, requiring changing NADMO's framework and an 
approach that unites Ghana beyond competing loyalties to ethnicities, tribes, and political entities (Oteng-Ababio, 2013).

Ghana is facing a crisis in electrical power due to economic growth outpacing the supply of electricity in the nation (Kumi, 2017). The low reservoir levels in Akosombo Dam compound the problems to increase electricity generation, and the Electric Corporation of Ghana (ECG) is building conventional generating plants. According to Laary (2014), Ghana is facing an energy crisis that negatively affects business operations and further economic growth. Erratic power supply and uncoordinated outages are widespread, affecting business operations and damaging electronic and other electrical machinery or equipment. The constant outages and power transmission losses mean an additional loss of income for ECG with numerous technical and operational crisis problems. This historically unreliable energy supply or blackouts nicknamed "Dumsor," a term coined by Ghanaians due to the irregularity and unpredictability of power supply in the country, has impacted the hospitality industry (Boakye, Twenefour, and McArthurFloyd, 2016) and several aspects of the economy (Danso-Wiredu, Dadson, and AmoakoAndoh, 2017), especially the private sector. Overall, estimates of the economic impacts of these load-shedding practices exceed US $\$ 2$ million each day, with incalculable costs incurred to social development Ruiter (2016). These practices can cause a significant retrenchment of the country's economic growth since the energy sector is a dominant state-owned enterprise, and hence remains an important growth engine for the economy (Ohemeng, Oboubisa Darko, and Amoako-Asiedu, 2019; Diawuo and Kaminskic, 2017; Eshun and Amoako-Tuffour, 2016; Kumi, 2017).

Risks and crisis events are inherent in many industries, such as mining, but they tend to be higher in developing nations. A case study (Agyemang, 2003) focusing on causes of crises and management in the Ghanaian mining industry and at Bogoso Gold Limited found that the company could deal with risk and handled crisis events effectively in the past. However, Agyemang noted that the Ghanaian mining industry should be better prepared to deal with potential crises due to the illegal small-scale mining and the local artisanal gold miners (i.e., galamsey).

Other types of potential crisis events in Ghana include the following: pest and insect infestation (armyworm, anthrax, blackfly, locust, larger grain borer), geological/nuclear radiological (earthquakes, tsunamis, gas emission, landslides), fires and lightning disasters (bush or wildfires, domestic, commercial, industrial fires), diseases and epidemics (cholera, yellow fever, cerebrospinal, meningitis, pandemic influenza, etc.), 
human-induced disasters (social conflicts, vehicular and aviation accidents, lake/boat accidents, marine, and railway disasters, etc.). In public health emergency preparedness alone, many disparate laws and jurisdictions create systemic and administrative impediments to effective crisis management and prevention programs (Norman, 2009).

\section{HYPOTHESIS DEVELOPMENT}

The present study examines crisis perception and management approaches among managers in Ghanaian organizations. We begin by assessing the relationship between a crisis in an organization and its internal functionality or crisis readiness and examining specific crises and the perceived likelihood they will occur in the organization. Two hypotheses test the relationship between (1) crisis and internal functionality and (2) crisis and the perceived likelihood of the crisis.

\section{Crisis management internal functionality}

The critical components of an organization's internal functionality and whether it could be prepared or unprepared to deal with crisis events are shown in Figure 1. Typically, managers have eight tangible or imaginary scales regarding the following variables: perception of crises, experience with past crisis events, management planning efforts, patterns of organizational communication, availability of resources to address a crisis event, and the organizational structure and culture. Thus, achieving quick and effective responses when facing an actual crisis situation depends on the degree of concern within the organization that potential crisis events may occur (See Figure 1). 
Figure 1. Organizational internal functions affecting crisis preparedness

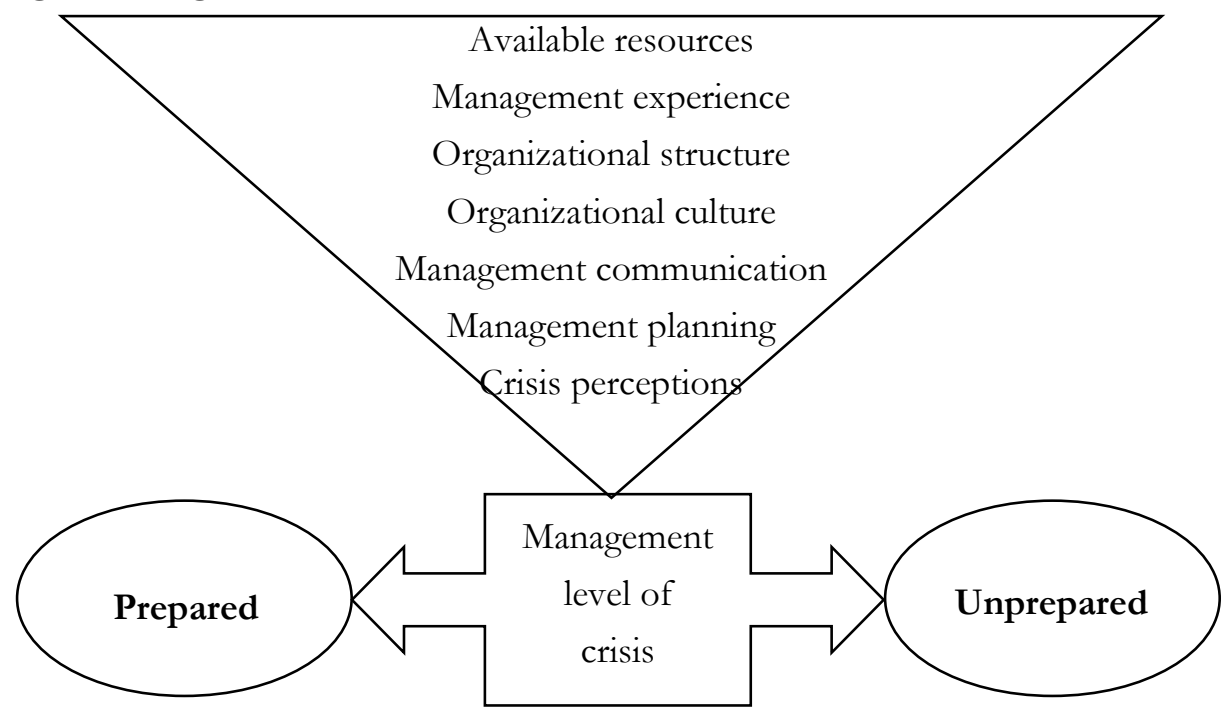

Adapted from: Parnell, Koseoglu, and Spillan (2010)

The development of the hypothesis for this study follows Parnell et al. (2010). It is generally accepted that successful organizations are aware of potential crisis events, practiced some scenarios or established procedures, and developed communication strategies critical to surviving a crisis (Gupta, 2011). This heightened managerial attentiveness is directly associated with two factors:

- Top management promotes a crisis-oriented culture (Dadzie et al., 2012), including support for the Crisis Management Team (CMT) (Marra, 1998; Smith, 1990).

- Past crises serve as learning exercises and prompt managers to become more concerned about future ones.

In general, organizations in emerging nations are not as prepared as their counterparts in developed countries to address crises (Deniz and Sağlam, 2007; Uzun, 2001).

As such, we posit that:

- H1: Managers in Ghanaian firms report relatively lower internal functionality than their counterparts in the developed world.

\section{Crisis concern}


A crisis event can be traced to three elements: (1) A trigger event that creates a significant change in the organization, (2) perceived ability among managers to cope with the change, and (3) a direct threat to the organization's survival and essential performance capabilities. A proactive approach is critical (Pearson and Mitroff, 1993; Penrose, 2000; Shrivastava, 1993).

Occasionally, effective crisis responses may help mitigate negative influences and lead to positive outcomes (Fearn-Banks, 1996). When managers view them as opportunities, they tend to see them as more controllable and involve more members in the resolution process (Jackson and Dutton, 1988; Lalonde, 2007). Perceiving a crisis as a threat typically increases crisis concern and reduces information availability and sharing. Hence, how a crisis is perceived can influence how an organization is willing to allocate appropriate resources and executive crisis management activities. Moreover, firms that have experienced a serious crisis tend to display higher attentiveness and concern for crisis events and are more likely to establish and support CMTs. Also, crisis events are more common in emerging economies like Ghana (Arpan and Sun, 2006).

Therefore, we expect that:

- H2: Managers in Ghanaian organizations perceive the likelihood of a crisis to be higher than do their US counterparts.

Previous crisis experience by managers is a significant influence on their concerns concerning a future crisis. In other words, experience serves as motivation for establishing crisis management responsiveness systems.

\section{METHODS}

This study uses a modified crisis readiness scale developed and tested by Rousaki and Alcott (2007). This scale was developed to study crisis management among hotel managers in the UK, a developed country. Because of its applicability, along with a lack of specialized instruments designed for developing nations, we have modified it for analyzing the conditions in Ghana. The eleven-item scale assesses the organization's internal functionality (OIF), including the organization's ability to provide a quick response to a crisis, its access to crisis management resources, and the presence of adequate strategic crisis planning (See Table 1). 
Table 1: Scale items and factor loadings: organization internal functionality

\begin{tabular}{|c|c|c|}
\hline Variable & Item narrative & Factor loading * \\
\hline OIF 1 & I have high accessibility to crisis management resources & .746 \\
\hline OIF 2 & $\begin{array}{l}\text { The organization has an adequate budget in its strategic plans in case of } \\
\text { a crisis situation }\end{array}$ & .787 \\
\hline OIF 3 & The organization has an adequate crisis management plan & .799 \\
\hline OIF 4 & $\begin{array}{l}\text { I am well informed about the resources and tools allocated for crisis } \\
\text { response }\end{array}$ & .758 \\
\hline OIF 5 & The organization views crisis management as a corporate goal & .794 \\
\hline OIF 6 & The members of the organization are trained to handle a crisis situation & .753 \\
\hline OIF 7 & The organization will quickly recover after a crisis situation & .775 \\
\hline OIF 8 & $\begin{array}{l}\text { The organization rewards employees for their part in detecting and } \\
\text { reporting potential crisis signs }\end{array}$ & .771 \\
\hline OIF 9 & $\begin{array}{l}\text { Key employees of the organization are well informed about the } \\
\text { resources and tools allocated for crisis response }\end{array}$ & .630 \\
\hline OIF 10 & $\begin{array}{l}\text { I am authorized to use the budget of the organization in order to cope } \\
\text { with a crisis }\end{array}$ & .360 \\
\hline OIF 11 & The organization's culture will encourage its ability to manage a crisis & .833 \\
\hline
\end{tabular}

* Coefficient alpha $=.913 ; 54.5 \%$ of the variance was explained by one factor.

Survey adapted from: Parnell, Koseoglu, and Spillan (2010)

The survey instrument also included demographic and personal questions (age, gender, management, organizational experience, and position in the firm).

A total of 251 surveys were included in the sample. We collected data from managers located in the Accra-Tema metropolitan area. The sample included small and large organizations, domestic and global enterprises, and manufacturing and service firms. The surveys were distributed by hand and collected in person.

Males and females were equally represented (121 each; 9 did not respond). The large number of females is intriguing given the higher proportion of males in the workforce. Respondents were across management levels in both genders, with lower and middle comprising the most prominent groups. The average age for the composite sample was 24 years, with respondents reporting six years of management experience and five years of experience with their present organization. Only $39 \%$ and $42.6 \%$ of respondents were aware of a crisis team and a crisis plan in their organizations, respectively. Interestingly, $23.1 \%$ and $28.7 \%$ of respondents did not know if their organizations had a crisis team or a crisis plan, respectively. We provide a summary of sample data in Table 2. 
Table 2. Sample grand total $=251$

\begin{tabular}{|c|c|c|c|c|c|}
\hline Variable & Number & $\begin{array}{l}\% \text { of } \\
\text { total }\end{array}$ & Variable & Number & $\begin{array}{l}\% \text { of } \\
\text { total }\end{array}$ \\
\hline Gender & & & $\begin{array}{l}\text { Crisis team in the } \\
\text { organization }\end{array}$ & & \\
\hline Males & 121 & 48.2 & Yes & 98 & 39.0 \\
\hline Females & 121 & 48.2 & No & 95 & 37.8 \\
\hline Not reported & 9 & 3.6 & Do not know & 58 & $23.1 \%$ \\
\hline Management & & & $\begin{array}{l}\text { Crisis plan for the } \\
\text { organization }\end{array}$ & & \\
\hline Non-managers & 46 & 18.3 & Yes & 107 & 42.6 \\
\hline Lower managers & 62 & 24.7 & No & 72 & 28.7 \\
\hline Middle managers & 102 & 40.6 & Do not know & 72 & 28.6 \\
\hline Top managers & 35 & 13.9 & Owned by foreign firm & & \\
\hline \multirow[t]{3}{*}{ Not reported } & 6 & 2.4 & Yes & 78 & 31.2 \\
\hline & & & No & 172 & 68.8 \\
\hline & & & Not reported & 1 & 0.4 \\
\hline \multicolumn{3}{|c|}{ Descriptive data } & Mean (years) & \multicolumn{2}{|c|}{$\begin{array}{l}\text { Std. deviation } \\
\text { (years) }\end{array}$} \\
\hline \multicolumn{3}{|l|}{ Age $(n=240)$} & 24.0 & & 22.2 \\
\hline \multicolumn{3}{|c|}{ Management experience $(\mathrm{n}=236)$} & 6.0 & & 5.5 \\
\hline \multicolumn{3}{|c|}{ Experience with organization $(n=239)$} & 5.0 & & 5.0 \\
\hline
\end{tabular}

\section{FINDINGS}

It was necessary to assess the reliability of the OIF scale before proceeding to test the hypotheses. Table 1 displays the results of strong support for the OIF scale when responses were assessed individually. All items produced factor loadings above .700 with only two exceptions while only one item loaded below .500. The coefficient alpha for the scale was .913.

Table 3 ranks the average concern for a variety of potential crises. The greatest concern was associated with fraud and operational crises. The least concern was associated with natural disasters. 
Table 3. Factor analysis results: crisis readiness scale

\begin{tabular}{|c|c|c|c|}
\hline $\begin{array}{l}\text { Category and } \\
\text { Variable }\end{array}$ & Crisis & Mean & $\begin{array}{c}\text { Std. } \\
\text { Deviation }\end{array}$ \\
\hline Fraud 2 & Corruption by management & 3.31 & 1.413 \\
\hline Fraud 1 & Embezzlement by employee(s) & 3.27 & 1.479 \\
\hline Fraud 4 & Theft of company property or materials & 3.08 & 1.540 \\
\hline Operational 3 & Lost records permanently due to computer breakdown & 2.96 & 1.343 \\
\hline Operational 1 & Theft or disappearance of records & 2.93 & 1.454 \\
\hline Operational 8 & $\begin{array}{l}\text { Breakdown of a major piece of production/service } \\
\text { equipment }\end{array}$ & 2.92 & 1.413 \\
\hline Fraud 5 & Employee violence at the workplace & 2.90 & 1.499 \\
\hline Fraud 3 & Corporate espionage & 2.88 & 1.444 \\
\hline Operational 5 & Major industrial accident & 2.86 & 1.470 \\
\hline Operational 2 & Lost record permanently due to fire & 2.83 & 1.539 \\
\hline Operational 6 & Major product/service malfunction & 2.68 & 1.299 \\
\hline Natural disaster 1 & Flood & 2.50 & 1.500 \\
\hline Operational 9 & $\begin{array}{l}\text { Internet site disrupted due to hacker or some other act of } \\
\text { vengeance }\end{array}$ & 2.40 & 1.457 \\
\hline Legal 1 & Consumer lawsuit & 2.38 & 1.444 \\
\hline Publicity 2 & Product sabotage & 2.36 & 1.342 \\
\hline Legal 2 & Employee lawsuit & 2.36 & 1.439 \\
\hline Legal 3 & Government investigation & 2.35 & 1.554 \\
\hline Legal 4 & Product recall & 2.32 & 1.501 \\
\hline Operational 4 & Computer system invaded by hacker & 2.31 & 1.353 \\
\hline Operational 7 & Death of a key executive & 2.25 & 1.460 \\
\hline Publicity 3 & Negative media coverage & 2.24 & 1.384 \\
\hline Publicity 1 & Boycott by consumers or the public & 2.14 & 1.299 \\
\hline Natural disaster 4 & Hurricane & 1.82 & 1.472 \\
\hline Natural disaster 5 & Earthquake & 1.73 & 1.259 \\
\hline Natural disaster 2 & Tornado & 1.59 & 1.230 \\
\hline Natural disaster 3 & Snowstorm & 1.51 & 1.187 \\
\hline
\end{tabular}

Definitions adapted from: Parnell, Koseoglu, and Spillan (2010)

We asked respondents to rate their concern for each of 26 crisis events on a scale of 1 (low) to 5 (high). They were also asked if they have experienced the crisis during the previous year or three years. We conducted t-tests to determine if the level of concern for each crisis was associated with experience with that crisis. Composite results in Table 4 provide support for a link between a crisis during the past year and crisis concern in all 26 events. They also support a link between a crisis occurring during the past three years and crisis concern in 23 of the 26 events. 
Table 4. Results of t-tests assessing crisis concern and crisis occurrence

\begin{tabular}{|c|c|c|c|c|}
\hline $\begin{array}{c}\text { Category and } \\
\text { variable }\end{array}$ & $\begin{array}{c}\text { Crisis occurred in past year } \\
\text { (F-value) }\end{array}$ & $\begin{array}{c}\text { Signif. } \\
\text { level }\end{array}$ & $\begin{array}{c}\text { Crisis occurred in past } \\
3 \text { years (F-value) }\end{array}$ & $\begin{array}{c}\text { Signif. } \\
\text { level }\end{array}$ \\
\hline Operational 1 & 5.436 & .000 & 3.035 & .018 \\
\hline Operational 2 & 16.982 & .000 & 7.717 & .000 \\
\hline Operational 3 & 15.996 & .000 & 9.626 & .000 \\
\hline Operational 4 & 28.102 & .000 & 21.554 & .000 \\
\hline Operational 5 & 13.720 & .000 & 15.190 & .000 \\
\hline Operational 6 & 21.503 & .000 & 11.819 & .000 \\
\hline Operational 7 & 5.258 & .000 & 22.205 & .000 \\
\hline Operational 8 & 11.242 & .000 & 21.505 & .000 \\
\hline Operational 9 & 4.165 & .000 & 6.122 & .000 \\
\hline Publicity 1 & 4.956 & .001 & 1.223 & .302 \\
\hline Publicity 2 & 10.330 & .000 & 7.341 & .000 \\
\hline Publicity 3 & 9.162 & .000 & 8.417 & .000 \\
\hline Fraud 1 & 29.728 & .000 & 18.610 & .000 \\
\hline Fraud 2 & 16.373 & .000 & 13.621 & .000 \\
\hline Fraud 3 & 22.718 & .000 & 8.569 & .000 \\
\hline Fraud 4 & 16.131 & .000 & 0.730 & .572 \\
\hline Fraud 5 & 22.979 & .000 & 6.093 & .000 \\
\hline Natural disaster 1 & 34.418 & .000 & 31.888 & .000 \\
\hline Natural disaster 2 & 4.256 & .002 & 3.598 & .007 \\
\hline Natural disaster 3 & 4.116 & .003 & 1.726 & .145 \\
\hline Natural disaster 4 & 20.360 & .000 & 18.639 & .000 \\
\hline Natural disaster 5 & 6.192 & .000 & 1.026 & .000 \\
\hline Legal 1 & 19.162 & .000 & 9.644 & .000 \\
\hline Legal 2 & 7.709 & .000 & 8.430 & .000 \\
\hline Legal 3 & 21.705 & .000 & 5.492 & .000 \\
\hline Legal 4 & 16.322 & .000 & 10.643 & .000 \\
\hline
\end{tabular}

The OIF was not significantly associated with management experience, organizational experience, number of employees in the organization, or annual revenue. However, OIF was significantly associated with the age of the organization, with a correlation of .150 and a significance level of .028. Analysis of variance (ANOVA) tests was conducted to assess the associations between OIF and management level of the respondent, existence of a crisis team, existence of a crisis plan, and firm ownership status. We found significant in all instances (See Table 5). The OIF was highest among middle and upper managers, among respondents who were aware of a crisis plan and a crisis team in the organization and in organizations owned by foreign firms. 
Table 5. ANOVA results for OIF

\begin{tabular}{lcc}
\hline Variable & Cases* & Mean \\
\hline Management level (F-value $=5.504 ;$ significance level = .001) & \\
Non-managers & 43 & -.434 \\
Lower managers & 54 & -.095 \\
Middle managers & 91 & .104 \\
Top managers & 33 & .431 \\
Crisis team in the organization & (F-value $=8.866$, significance level $=.000)$ \\
Yes & 89 & .255 \\
No & 81 & -.354 \\
Do not know & 54 & .110 \\
Crisis plan for the organization (F-value $=5.686$, significance level $=.004)$ \\
Yes & 100 & .194 \\
No & 59 & -.348 \\
Do not know & 65 & .017 \\
Organization owned by foreign firm (F-value $=20.261 ;$ significance level $=.000)$ \\
Yes & 72 & .419 \\
No & 152 & -.199 \\
\hline
\end{tabular}

* A small number of cases could not be included in each ANOVA test because of missing data.

\section{DISCUSSION}

Several findings warrant additional discussion. Resources and the planning required for crisis management may not be a primary consideration for Ghanaian managers. Turbulent and dynamic environments provide decision-makers with experience and practice that suggests preventive action may not be possible or effective. Still, a prompt response is typically the best course of dealing with crises (Parnell, 2021). Nevertheless, even with a comprehensive plan in place, an organization's responses to a particular crisis cannot be foreseeable nor made universal.

The broad concern for crises associated with fraud is intriguing. The prevalence of fraud may be attributable to the existence of weak corporate governance, poor accounting practices, procedures, and policies, the lack of client due diligence, ineffective internal control systems, policies and procedures, perverted social values, slow and circuitous judicial process, and the fear of negative publicity (Dhitima, 2016). In the absence of adequate and appropriate checks and balances, corrupt managers and employees exploit the system and vulnerable customers using shady schemes that include manipulative 
financial deception. This deception for one's gain at the expense of others is often in the form of theft, corruption, conspiracy, embezzlement, asset misappropriation, money laundering, bribery, and a position of trust or fiduciary relationship (Bonsu, Dui, Muyun, Asare, and Amankwaa, 2018). It is not surprising that of the fraud variables corruption by management, embezzlement by employees, and the theft of company property or materials were rated relatively higher.

While the deleterious effect of fraud on any economy is quite apparent, for a small developing country like Ghana, it could result in job and income loss for many households, which could plunge the economy into a recession. For example, a study found that besides macroeconomic instabilities and panic withdrawals, the collapse of several microfinance institutions was due to unduly risky, unethical, or illegal practices as well as simple mismanagement and disregard for due diligence (Boateng, Nortey, Asamanin Barnie, Dwumah, Acheampong, and Ackom-Sampene, 2016). This had a significant impact on the livelihood of many workers in the financial sector, perhaps explaining the heightened concern expressed by participants in the study.

The relatively low concern for crises associated with natural disasters is understandable, as the likelihood of such crises are typically linked to geographical considerations (e.g., snowstorms are not a concern in hot climates). However, a few regions of the country are located in earthquake-prone zones. Commodity shortages (including foreign exchange), currency and exchange rate instability, risk of inflation, disease outbreaks, political upheavals, intermittent power outages, and other external forces tend to create more business crises than natural disasters. Organizational management planning efforts are therefore often geared toward such events. Nonetheless, more than half of the managers surveyed reported not having a CMT or plan in place to mitigate a crisis event. This deficiency does not bode well for businesses in Ghana since crises are inevitable. While there is no infallible method to avoid a crisis, the ability to perceive a crisis and the readiness or preparedness of management to address its incidence or curb its impact on a firm's performance and reputation is key to business survival.

\section{CONCLUSIONS}

This study surveyed the perceptions and experiences of Ghanaian managers concerning crisis events and crisis management. It supports the notion that managers in Ghanaian 
organizations perceive the likelihood of crisis events differently from their counterparts in many Western organizations. Only 39.0\% of the Ghanaian respondents in this study reported that their organization had formed a CMT.

The findings demonstrated that multinational firms operating in Ghana are more likely than domestic firms to prepare for crisis events. Organizations in Ghana do not tend to establish management functions to address impending or existing crises in the same fashion as those in developed nations. It appears that smaller businesses experience fewer crisis events relative to larger organizations and their perceived needs to plan for a crisis is not as strong. In general, smaller companies are not that concerned about crisis issues, and subsequently and few have CMTs. Although Ghanaian firms may have recognized the need for crisis preparation, they do not tend to invest time, energy, and resources consistent with Western firms.

This study recommends that all Ghanaian businesses should adopt crisis management plans, form CMTs, identify worst-case scenarios, and practice mock disasters. With rapid economic changes in recent years, emerging economies like Ghana have attracted MNCs to set up local operations. Their influence is likely to have a positive effect on improving the crisis management process in Ghana. When a crisis occurs, concern for that crisis increases within the organization. This observation is intuitive. However, Ghanaian managers' lack of confidence about their crisis preparedness may be associated with the lack of resources or management traditions that exist within Ghanaian firms as well as an inadequate awareness of the potential damage that may result from their mishandling a crisis. Organizational life in Ghana fluctuates rapidly because of changes in both the global and domestic environments. Hence, the fact that Ghanaian managers constantly grapple with crises may explain why their crisis perception level is relatively high.

Other findings include dealing with the culture and the political or governance that often create obstacles in crisis preparation and also managing with disasters. This often requires necessary changes at the national level and within national-based organizations as well as local authorities. In Ghana, this includes raising trust, expanding communication, and improving the operations of NADMO. For example, the crisis conditions with energy production and maintenance of the distribution grid are critical. The national ECG needs to focus on service delivery to provide individual and commercial customers with reliable power. Increasingly low reservoir levels are also part of the droughts that create many crisis conditions in agriculture and all industrial sectors that use electricity. This major 
challenge, along with other nature-based crisis events such as flooding, means the nation needs to develop sincere and trustworthy long-term contingency plans for dealing with climate change. Recurrent crisis events such as floods as well as industrial accidents force managers in Ghana to deal with them, but there seems to be an inadequate perception among them as to the costs of mismanaging these crises. This fining is also borne out by the experience of consultants to developing nation governments when they observe the pattern of the same disasters repeating and creating greater costs than would be the resources needed to prevent them.

When a crisis occurs, concern for that crisis increases. This observation is intuitive. However, the lack of confidence Ghanaian managers express regarding crisis preparedness may be associated with the lack of resources or management traditions in local Ghanaian firms. Organizational life in Ghana fluctuates rapidly because of changes in both the global and domestic environments. This is compounded by the chronic day-today business problems faced by Ghanaian organizations along with their managers' limited capacity and resources for incorporating crisis management.

Although Ghanaian firms may have recognized the need for crisis preparation, they do not tend to invest time, energy, and resources consistent with Western firms. With rapid economic changes in recent years, however, emerging economies like Ghana have attracted many MNCs. This influence is likely to have a positive effect on the crisis management process. The literature concerning the benefits of international business and MNC collaboration with indigenous firms is replete with positive examples for local employment as well as facilitating technology transfer and management know-how to developing nations. This study also demonstrates that MNC involvement in Ghana enhances the nation's crisis management skills. This benefit is particularly important during the increasingly challenging times of the pandemic as well for dealing with traditional crisis events in Ghana.

We identified several limitations of the current study. Although there are common management principles and similar crisis events, there are differences between nations and among developing countries regarding crisis management. We examined crisis perceptions and preparation in only one nation. Given the wide range of cultural and economic differences within Africa and between the African continent and other parts of the world, the findings in other emerging nations would likely differ. Hence, these findings are exploratory as to Ghana and should not infer links between strategic orientation and crisis 
management in other parts of the world. More research is needed in Ghana, and this study should be replicated in Sub-Saharan Africa.

Investigations in other emerging economies may confirm factors that are common or unique to such developing nations. Increased investment and trade within African nations and Ghana as well as other nations (e.g., the United States, China, and India) will likely broaden the significance and effect of crises that occur.

Our results also come from only a moderately sized sample and a simple statistical analysis. The findings show significant differences exist between both the expectations and the experiences of the survey respondents. A larger data set drawn from a broader crosssection of enterprises would strengthen our findings and conclusions.

The results of this study identify some of the perceptions, experiences, and problems that Ghanaian managers expressed in the area of crisis management, but more research is needed to provide additional solutions and practical approaches to better prepare and assist them in dealing with disasters.

\section{REFERENCES}

Acquaah, M. 2011. Business strategy and competitive advantage in family businesses in Ghana: The role of social networking relationships. Journal of Developmental Entrepreneurship 16: 103-126.

Agyapoing, A. and A. S. Muntaka. 2012. Strategic planning and performance of businesses in Ghana: A comparative study of micro, small, and large firms. International Business and Economics Research Journal 11: 1261-1268.

Agyapong, A. and R. B. Boamah. 2013. Business strategies and competitive advantage of family hotel businesses in Ghana: The role of strategic leadership. Journal of Applied Business Research 29: 531-544.

Agyemang, S. A. K. 2003. Risks and crises management in the Ghana mining industry: a case study. Unpublished Ph.D. Dissertation, Kwame Nkrumah University of Science and Technology.

Ahorlu, C. S. 2014. Crisis management preparedness in a Ghanaian research institute. International Journal of Management Sciences 4 (11): 506-513. 
Al-Nammari, F. and M. Alzaghal. 2015. Towards local disaster risk reduction in developing countries: Challenges from Jordan. International Journal of Disaster Risk Reduction 12: $34-41$.

Almoradie, A, M. M. de Brito, M. Evers, A. Bossa, M. Lumor, C. Norman, Y. Yacouba, and J. Hounkpe. 2020. Current flood risk management practices in Ghana: Gaps and opportunities for improving resilience. Journal of Flood Risk Management 13 (4): e12664.

Andah, W. E. I., N. van de Giesen, and C. A. Biney. 2003. Water, Climate, Food, and Environment in the Volta Basin, Project ADAPT - Adaptation strategies to changing environments.

https://www.academia.edu/506916/Water_climate_food_and_environment_in_the _Volta_Basin

Arpan, L. M. and H. Sun. 2006. The effect of country of origin on judgments of multinational organizations involved in a crisis. Journal of Promotion Management 12 (3/4): 189-214.

Balamir, M. 2002. Painful steps of progress from crisis planning to contingency planning: Changes for disaster preparedness in Turkey. Journal of Contingencies and Crisis Management 10 (1): 39-49.

Barton, L. 1993. Crisis in organizations: Managing and communicating in the midst of chaos. Cincinnati: Southwestern Publishing.

Bass, B. M. 1990. From transactional to transformational leadership: Learning to share the vision. Organizational dynamics 18 (3): 19-31.

Bass, B. M. 1996. Handbook of leadership: A survey of theory and research. New York: Free Press.

Bax, P., and E. Dontoh. 2014. Ghana turns to IMF for help as currency crisis deepens. Bloomberg News. August 4.

BBC News. 2007. UK's Tullow uncovers oil in Ghana http://news.bbc.co.uk/2/hi/business/6764549.stm

BBC News. 2012. Melcom shop collapse in Ghana: Negligence blamed https://www.bbc.com/news/world-africa-20250494

Boakye, N. A. B., F. B. Twenefour, and M. McArthur-Floyd. 2016. The impact of power outage "Dumsor" on the hotel industry: Evidence from Ghana. Journal of Energy Technologies and Policy 6 (8): 39-47.

Boateng, F. G., S. Nortey, J. Asamanin Barnie, P. Dwumah, M. Acheampong, and E. Ackom-Sampene. 2016. Collapsing microfinance institutions in Ghana: An account 
of how four expanded and imploded in the Ashanti region. International Journal of African Development $3 \quad$ (2): $\quad$ Article 5. https://scholarworks.wmich.edu/ijad/vol3/iss2/5

Bonsu, O.-A. M., L. K. Dui, Z. Muyun, E. K. Asare, and I. A. Amankwaa. 2018. Corporate fraud: Causes, effects, and deterrence on financial institutions in Ghana. European Scientific Journal $14 \quad$ (28): 315. https://doi.org/10.19044/esj.2018.v14n28p315

Caponigro, J. R. 1997. The crisis counselor: The executive's guide to avoiding, managing, and thriving on crises that occur in all businesses. Southfield, MI: Barker Business Books.

Caponigro, J. R. 2000. The crisis counselor: a step-by-step guide to managing a business crisis. McGraw-Hill.

Conill, J. 2013. Otra vida es posible: prácticas económicas alternativas durante la crisis. Otra vida es posible, $0-0$.

Coombs, W. 2007. Ongoing crisis communication: Planning, managing, and responding $2^{\text {nd }}$ ed. Thousand Oaks, CA: Sage.

Coombs, W. T. and S. J. Holladay. 2006. Unpacking the halo effect: Reputation and crisis management. Journal of Communication Management 10 (2): 123-137.

Crandall, W. and M. Menefee. 1996. Crisis management in the midst of labor strife: Preparing for the worst. SAM Advanced Management Journal 61 (1): 11-15.

Crandall, W. R., J. A. Parnell, and J. E. Spillan. 2014. Crisis Management: Leading in the new strategy landscape second edition. Thousand Oaks, CA: Sage Publications.

Dadzie, C. A., E. M. Winston, and K. Q. Dadzie, 2012. Organizational culture, competitive strategy, and performance in Ghana. Journal of African Business 13 (3): 172-182.

Deniz, M., and M. Sağlam. 2007. Kriz Dönemlerinde İşletme Stratejileri ve Malatya Organize Sanayi Bölgesinde Faaliyet Gösteren Tekstil İşletmelerinde Bir Uygulama. Elektronik. Sosyal Bilimler Dergisi (elektronik) 6 (20): 156-176.

Danso-Wiredu, E. Y., Y. I. Dadson, and F. O. Amoako-Andoh. 2016. Social, economic and environmental impacts of the recent electricity crisis in Ghana: A study of Winneba, Journal of Social Sciences 49 (3-1):277-288, DOI: 10.1080/09718923.2016.11893621

Dhitima, P. C. 2016. Ten Risk Questions for Every MFI Board: A Running with Risk Project Expert Exchange, Centre for Financial Inclusion. Accion [Online] http:/ / wmw. accion. org/center-for-financial-inclusion 
Diawuo, F. A. and J. Kaminskic. 2017. An analysis of the Ghanaian power generation sector using an optimization model. Journal of Power Technologies 97: 15-27.

Eshun, M. E. and J. Amoako-Tuffour. 2016. A review of the trends in Ghana's power sector. Energy Sustainability and Society 6: 1-9. https://doi.org/10.1186/s13705-0160075-y

Evans, N. and S. Elphick 2005. Models of crisis management: An evaluation of their value for strategic planning in the international travel industry. International Journal of Tourism Research 7 (3): 135-150.

Faria, F. 2004. Crisis management in sub-Sabaran Africa: The role of the European Union (Vol. 51). Paris, France: European Union Institute for Security Studies.

Fearn-Banks, K. 1996. Crisis Communications: A Casebook. Approach. Mahwah, NJ: Lawrence Erlbaum Associates.

Fening, F. A., G. Pesakovic, and P. Amaria. 2008. Relationship between quality management practices and the performance of small and medium size enterprises (SMEs) in Ghana. International Journal of Quality and Reliability Management 25: 694708.

Garuba, C. A. 1998. Capacity building for crisis Management in Africa. National War College (Nigeria).

Ghana Business Forecast Report Q1 (2010). Business Monitor, November 2009. http://www.reportlinker.com/p0165580/Ghana-Business-Forecast-ReportQ1.html.

Greening, D. and R. Johnson. 1996. Do managers and strategy matter? A study in crisis. Journal of Management Studies 33 (1): 25-51.

Gupta, R. 2011. Corporate communication: A strategic tool for crisis management. Journal of Economic Development, Management, IT, Finance and Marketing 3 (2): 55-67.

Herbane, B. 2013. Exploring crisis management in UK small- and medium-sized enterprises. Journal of Contingencies and Crisis Management 21 (2): 82-95.

Hofstede, G. 1980. Motivation, leadership and organization: Do American theories apply abroad? Organizational Dynamics 9: 42-63.

Hofstede, G. 1991. Cultures and organizations: Software of the mind. London: McGraw-Hill.

Hope, K. R. 2002. From crisis to renewal: Development policy and management in Africa (Vol. 5). Brill.

House, R., N. S. Wright, and R. N. Aditya. 1997. Cross-cultural research on organizational leadership. A critical analysis and a proposed theory. In P.C. Early and M. Erez 
(Eds.), New perspectives on international industrial/ organizational psychology. San Francisco, CA: Lexington Press.

Irvine, R. and D. Millar. 1997. Multiplying the effects: Factors influencing media coverage of business crisis. Proceedings of the 6th Annual Conference on Crisis Management, Las Vegas, Nevada.

Jackson, S. E. and J. E. Dutton. 1988. Discerning threats and opportunities. Administrative Science Quarterly 33: 370-387.

James, E. H., L. P. Wooten, and K. Dushek. 2011. Crisis management: Informing a new leadership research agenda. Academy of Management Annals 5 (1): 455-493.

Koc, E. 2013. Power distance and its implications for upward communication and empowerment: Crisis management and recovery in hospitality services. International Journal of Human Resource Management 24: 3681-3696.

Kumi, E. N. 2017. The electricity situation in Ghana: Challenges and opportunities. CGD Policy Paper. Washington, DC: Center for Global Development. https://www.cgdev.org/publication/electricity-situation-ghana-challenges-andopportunities

Lalonde, C. 2007. Crisis management and organizational development: Towards the conception of a learning model in crisis management. Organization Development Journal 25 (1): 17-26.

Lalonde, C. and C. Roux-Dufort. 2013. Challenges in teaching crisis management: Connecting theories, skills, and reflexivity. Journal of Management Education 37 (1): 21 50.

Laary, D. 2014. Ghana: Cholera kills hundreds. The Africa Report. November 21. http://www.theafricareport.com/West-Africa/ghana-cholerakills-hundreds.html

Lerbinger, O. 1997. The crisis manager: facing risk and responsibility. Mahwah, NJ: Lawrence Erlbaum Associates.

Lewis, P. and J. W. Harbeson. 2016. Coping with crisis in African states. Lynne Rienner Publishers.

Leyro, S. P. and D. L. Stageman. 2018. Crimmigration, deportability and the social exclusion of noncitizen immigrants. Migration Letters 15 (2): 255-265. https://biglawbusiness.com/insight-immigration-enforcement-actions-magnifyneed-for-employers-to-prepare

London, R. and S. L. Hart. 2004. Reinventing strategies for emerging markets: Beyond the transnational model. Journal of International Business Studies 35: 350-370. 
Mahmoud, M. 2011. Market orientation and business performance among SMEs in Ghana. International Business Research 4: 251-261.

Mahul, O. 2001. Managing catastrophic risk through insurance and securitization. American Journal of Agricultural Economics 83 (3): 656-661.

Marra, F. 1998. Crisis communication plans: Poor predictors of excellent crisis public relations. Public Relations Review 24 (1): 461-474.

McCartney, M., W. Crandall, and C. Ziemnowicz. 1999. Why plan for something bad if it may not happen? (Or- is crisis management stuff just another fad?). Internal Auditing 14 (1): 11-17.

Mitroff, I. I. 1988. Crisis management: Cutting through the confusion. Sloan Management Review 29 (2): 15-20.

Mitroff, I. I., T. Pauchant, M. Finney, and C. Pearson. 1989. Do (some) organizations cause their own crises? The cultural profiles of crisis-prone vs. crisis-prepared organizations. Industrial Crisis Quarterly 3 (4), 269-283.

Mullins, S. 2005. Ethical crisis management. International Journal of Management and Decision Making 6: 372-381.

NADMO. 2020. Vision and mission. National Disaster Management Organisation of Ghana (website). http://www.nadmo.gov.gh/index.php/about/vision-mission

Newkirk, R. T. 2001. The increasing cost of disasters in developed countries: A challenge to local planning and government. Journal of Contingencies and Crisis Management 9 (3): 159-170.

Norman, I. D. 2009. Ghana's public health and legal preparedness for disaster and emergencies, Unpublished Ph.D. Dissertatio, University of Ghana. http://ugspace.ug.edu.gh/handle/123456789/23689

Ohemeng, F. L. K., T. Obuobisa Darko, and E. Amoako-Asiedu. 2019. Employee engagement and task performance in state-owned enterprises in developing countries: The case study of the power sector in Ghana. Journal of Public Affairs 20 (2): e2021. doi: 10.1002/pa.2021

Olsen, G. R. 2011. Civil-military cooperation in crisis management in Africa: American and European Union policies compared. Journal of International Relations and Development 14 (3): 333-353.

Oteng-Ababio, M. 2013. 'Prevention is better than cure': assessing Ghana's preparedness (capacity) for disaster management. Jàmbá: Journal of Disaster Risk Studies 5 (2): 1-11 
Ouedraogo, A. 2007. Crisis management and corporate strategy in African firms: Towards a contingency approach. Journal of Contingencies and Crisis Management 15 (4): 220-231.

Parnell, J. A. 2021. An ounce of prevention: Why promotes crisis readiness and how does it drive performance? American Business Review 24 (1): 90-113.

Parnell, J. A. 2018. Nonmarket strategy in business organizations: A global assessment. New York: Springer Publications.

Parnell, J.A., W. R. Crandall, P. Xihui, and Z. Long 2007. When crisis management goes abroad: The demise of SK-II in China. Journal of International Business Research and Practice 1: 38-49.

Parnell, J. A., M. A. Koseoglu, and J. E. Spillan. 2010. Crisis readiness in Turkey and the United States. Journal of Contingencies and Crisis Management 18: 108-116.

Pearson, C., and I. Mitroff. 1993. From crisis prone to crisis prepared: A framework for crisis management. Academy of Management Executive 71: 48-59.

Penrose, J. M. 2000. The role of perception in crisis planning. Public Relations Review 26 (2): $155-171$.

Piotrowski, C., J. D. Watt, and T. Armstrong. 2010. The interdisciplinary nature of the field of crisis management: A call for research collaboration. Organization Development Journal 28 (3): 85-91.

Ralston, D. A., D. H. Holt, R. H. Terpstra, and Y. Kai-Cheng. 2008. The impact of national culture and economic ideology on managerial work values: A study of the United States, Russia, Japan, and China. Journal of International Business Studies 39: 826.

Reid, D. M. 2000. Chaos in Korea: Discerning opportunities. International Journal of Management and Decision Making 1: 44-67.

Rousaki, B. and P. Alcott. 2007. Exploring the crisis readiness perceptions of hotel managers in the UK. Tourism and Hospitality Research 7: 27-38.

Ruiter, C. 2016. Doomed by Dumsor? Impacts and implications of Ghana's load shedding crisis. Overcoming crises: challenges and opportunities. Potentia: Journal of International Affairs 7: 1-5. DOI: https://doi.org/10.18192/potentia.v7i0.4422

Sawalha, I. H. S., L. F. Jraisat, and K. A. M. Al-Quduh. 2013. Crisis and disaster management in Jordanian hotels: Practices and cultural considerations. Disaster Prevention and Management 22 (3): 210-228.

Seeger, M., T. Sellnow, and R. Ulmer. 1998. Communication, organization, and crisis. Communication Yearbook 21: 231-275. 
Sellnow, T. and M. Seeger. 2001. Exploring the boundaries of crisis communication: The case of the 1997 Red River Valley flood. Communication Studies 52 (2): 153-167.

Shapiro, A., G. Contreras, and D. Blanchard. 2019. "Months after massive ICE raid, residents of a Mississippi town wait and worry" NPR, https://www.npr.org/2019/11/17/778611834/months-after-massive-ice-raid-

residents-of-a-mississippi-town-wait-and-worry

Shrivastava, P. 1993. Crisis theory/practice: Towards sustainable development. Industrial and Environmental Quarterly 7 (1): 23-42.

Simbo, A. K. 1993. Catastrophe planning and crisis management. Risk Management, 40(3), 64-67.

Smith, D. 1990. Beyond contingency planning: Towards a model of crisis management. Industrial Crisis Quarterly 4 (4): 263-275.

Somers, S. 2009. Measuring resilience potential: An adaptive strategy for organizational crisis planning. Journal of Contingencies and Crisis Management 17 (1): 12-23.

Spillan, J. E. and C. Ziemnowicz. 2007. Perception of crisis management: a comparative analysis of Guatemalan and US small businesses. Southeastern Chapter of Informs Proceedings, 590-603. http://www.conferencemgt.com/presseinforms/ SEINFORMS\%202007\%20- \%20Proceedings/proc/p070525029.pdf

US Department of State. 2019. U.S. Relations With Ghana. Bureau of African Affairs. March 6. https://www.state.gov/u-s-relations-with-ghana/

Uzun, Ö. 2001. Patient satisfaction with nursing care at a university hospital in Turkey. Journal of Nursing Care Quality, 16 (1), 24-33.

Wasti, S. A., H. H. Tan, H. H. Brower, and C.. Önder. 2007. Cross-cultural measurement of supervisor trustworthiness: An assessment of measurement invariance across three cultures. The Leadership Quarterly 18: 477-489.

Wilderoter, D. 1987. Crisis management: a new plan is necessary. National Underwriter (Property/Casualty/Employee Benefits) 91 (33): 34-35.

Wester, M. 2009. Cause and consequences of crises: How perception can influence communication. Journal of Contingencies and Crisis Management 17 (2): 118-125.

Zhang, Y., Z. Zhang, and Z. Liu. 2007. Choice of entry modes in sequential FDI in an emerging economy. Management Decision 45: 749-772.

Zhou, K. Z., D. K. Tse, and J. J. Li. 2006. Organizational changes in emerging economies: Drivers and consequences. Journal of International Business Studies 37: 248-263. 